Universidad de Lima

Facultad de Derecho

Carrera de Derecho

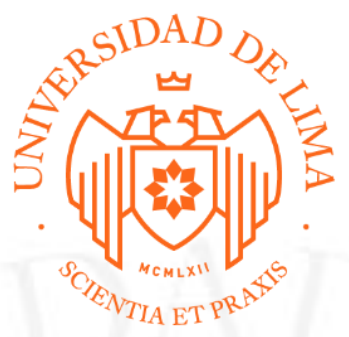

\title{
CIVIL: "RETRACTO" Y ADMINISTRATIVO: "ACCIÓN CONTENCIOSO ADMINISTRATIVA"
}

Trabajo de suficiencia profesional para optar el Título Profesional de Abogado

\section{Valeria Anaís Estrada Pérez}

Código 20130475

$$
\text { Lima - Perú }
$$

Setiembre de 2019 


\section{CIVIL: "RETRACTO"}

Materia: Retracto

Expediente $\mathrm{N}^{\circ}$ 1979-2010-01501-JR-CI-02

\section{RESUMEN}

El presente proceso se inició con la demanda interpuesta por el interesado, quien solicitó subrogarse en el lugar de los compradores del inmueble ubicado en el primer piso del edificio materia bajo litigio, pues consideraba ser titular del derecho de retracto. En este caso, ambas instancias judiciales declararon fundada la demanda; sin embargo, al revisar la sentencia emitida por la Sala, la Corte Suprema determinó que el demandante no cumplía con los supuestos establecidos en la norma para ejercer el retracto, y en consecuencia, declaró infundada la demanda.

\section{ADMINISTRATIVO: "ACCIÓN CONTENCIOSO ADMINISTRATIVA"}

Materia: Acción Contencioso Administrativa

Expediente $\mathrm{N}^{\circ}$ 2266-2015-0-1801-JR-CA-25

\section{RESUMEN}

El presente proceso se originó con la acción contencioso administrativa interpuesta por la Demandante, solicitando se declare la nulidad de la Resolución emitida por Indecopi que denegó el acceso al registro de su marca solicitada. Al respecto, en ambas instancias declararon fundada la demanda en razón de que no se producía confusión con otra marca registrada previamente, y tomando como indicio la coexistencia pacífica que dichos signos habían mantenido por varios años. 